\title{
The Ba'athist blackout? Selective goods provision and political violence in the Syrian civil war
}

Journal of Peace Research 2015, Vol. 52(1) 91-104

(C) The Author(s) 2014

Reprints and permission:

sagepub.co.uk/journalsPermissions.nav DOI: $10.1177 / 0022343314559437$ jpr.sagepub.com

๑SAGE

\author{
Alexander De Juan \& André Bank \\ German Institute of Global and Area Studies
}

\begin{abstract}
Many authoritarian regimes selectively provide critical segments of the population with privileged access to goods and services, expecting political support in return. This article is interested in the effects of this regime strategy: Is violent opposition less likely to occur in subnational regions bound to the ruling elite through such patron-client networks? For its empirical analysis, the article makes use of crowdsourcing data on the number and geospatial distribution of fatalities in the Syrian civil war from March 2011 to November 2012. In terms of selective goods provision, the focus is on the electricity sector. Satellite images of the earth at night are used to proxy spatial variations in the public distribution of electricity in times of power shortages. These data are complemented with information from the last Syrian population census of 2004. Estimations from fixed effect logit models lend support to the hypothesis that the risk of violence has been lower in subdistricts that have been favored by the ruling regime in terms of preferential access to material goods. This hypothesis is further corroborated with qualitative evidence from Syrian localities.
\end{abstract}

\section{Keywords}

civil war, crowdsourcing, nightlights, public goods, Syria

\section{Introduction}

Ruling elites cannot maintain their grip on power through violence and repression alone. Thus, in many cases they provide political or material goods and services to critical segments of the population in return for the latter's support or at least acquiescence. This article aims to investigate whether such patron-client networks reduce the risk of violent opposition from those parts of the population that have profited from selective redistribution.

Previous studies have found general evidence of the effectiveness of goods provision for political stability (Fjelde \& de Soysa, 2009; Taydas \& Peksen, 2012). Their cross-country focus does not allow, however, for the consideration of uneven redistribution. More often than not, the provision of goods and services is not used as an instrument to instill support among the masses, but rather to sustain the backing of specific segments of the population deemed particularly relevant.

We seek to contribute to the debate on the role of selective goods provision in regimes' attempts to create and uphold narrow patron-client networks for political stability. Syria serves as our empirical case. Rather than investigating overall levels of goods provision, we analyze actual preferential treatment of specific subnational regions. We want to ascertain whether Syrian subdistricts have been less at risk of experiencing violence in the current civil war if they have been favored by the state in the distribution of scarce material resources in the recent past.

Authoritarian regimes in the Middle East and elsewhere have been particularly reluctant to provide meaningful socio-economic information. Therefore, our analysis is based mainly on information that is outside of state control. First, we have made use of so-called crowdsourcing data on the number of fatalities in the Syrian civil war; these data stem from decentralized reports filed by Syrians through a publicly accessible

Corresponding author:

alexander.dejuan@giga-hamburg.de 
online platform. Second, we have used digitized highresolution satellite images of the earth at night to measure spatial unevenness in the provision of an essential public service: electricity. We have complemented these data with information from the last Syrian population census, undertaken in 2004, to build a new dataset of Syria's 274 subdistricts. We have performed crosssectional logit estimations, including fixed effects, at the level of the country's 14 governorates. Our findings lend support to the hypothesis that the risk of violence has been lower in subdistricts that have been favored by the ruling regime in terms of access to electricity in times of severe power shortages.

Our results contribute to ongoing discussions in various ways. To the best of our knowledge, we are the first to undertake a systematic study on the role of selective redistribution in political violence at the subnational level. Focusing on the allocation of material resources in times of scarcity, we propose an innovative approach for the conceptualization of preferential treatment and associated patron-client relations. Complementing comparable cross-country studies, we lend support to the hypothesis that the inclusion of citizens into state patronage networks can be an effective tool for encouraging compliance and reducing the risk of violent opposition.

\section{Selective redistribution and political stability}

Ruling elites need to secure support from among the population to reduce the risk of violent opposition. Certainly, regime repression and violence are central for political stability, as classic theorists ranging from Hannah Arendt to Thomas Hobbes and Niccolo Machiavelli have shown. However, no government, not even in highly authoritarian states, is likely to survive in the long run without a minimum degree of (quasi-)voluntary compliance (Gerschewski, 2013; Levi, 2006: 7), as the exclusive use of repression would be too costly to sustain over an extended period of time (Wintrobe, 2000: 388). Even though regimes might consider hard repression necessary to quell protests in the short or mid-term, its continuous, long-term use endangers the respective government both by draining crucial state resources and by increasing the likelihood of further and more violent rebellions. Non-repressive compliance can only be generated if the population receives something in return (Levi, 2006). Thus, ruling elites may try to win and uphold support by providing material incentives, such as economic benefits or specific tax rates (Acemoglu, Verdier \& Robinson, 2004; Gandhi \& Przeworski, 2007). Bueno de Mesquita et al. (2003) argue that public spending can be used to 'buy' allegiance and thus reduce the risk that the people will support challengers to the ruling elite.

Various empirical studies have investigated the role of goods provision in political violence. The findings, however, are mixed. For instance, Taydas \& Peksen (2012) find a significant negative connection between welfare spending and civil conflict onset, whereas Fjelde (2009) presents evidence revealing that goods provision in oil-rich states reduces the risk of violent opposition (see also Fjelde, 2010; Fjelde \& de Soysa, 2009). Bussmann (2009) does not find any significant connection between state expenditure on health and education and the onset of violent conflict.

Although we acknowledge that this research strand has contributed greatly to our understanding of the role of public spending, we argue that it neglects an essential feature of goods provision in many states: its very selective and targeted nature. In principle, regimes may try to provide benefits to the population at large in line with the arguments outlined above. However, the higher the number of beneficiaries, the lower the absolute value of rents for each beneficiary, including the members of the ruling regime themselves. For this reason, instead of distributing resources evenly and broadly, regimes tend to selectively distribute them to a limited number of people, basing their power on support from specific segments of the population (Acemoglu, Verdier \& Robinson, 2004; Wintrobe, 2000). The patron receives political compliance and support in return for preferential treatment of the clients.

We are interested in the efficacy of such a strategy. ${ }^{1}$ We assume that people will be less likely to engage in protest and violence against the ruling regime in regions that have been integrated into narrow patron-client networks and have profited from the state's policy in absolute and relative terms. People have an interest in upholding the status quo in order to retain their privileged position. The lower the support base of the

\footnotetext{
${ }^{1}$ There is a lively debate in the field of political economy about the determinants of material allocations (Burgess et al., 2010; Kramon \& Posner, 2012; Weinstein, 2011): do states reward traditional supporters, buy off political rivals, or invest in the 'swing' regions? Mirroring the inconclusive results of such studies, we believe that most regimes make use of selective redistribution in a complex and strategic way. They establish patron-client relations with different parts of society for various reasons - with some because of narrow ethnic ties, with others because they may pose a political risk, and with others because they are economically important. Given this equifinality, we focus on the effects rather than the causes of patron-client relations.
} 
opposition within a subnational region, the lower the risk that the region will be the locus of sustained antistate action (Wickham-Crowley, 1987).

\section{Conceptualizing and measuring selective redistribution}

A variety of measures have been used to capture subnational variations in the redistribution of material goods. Welfare spending is a prominent proxy (Taydas \& Peksen, 2012; Weinstein, 2011). Such an indicator, however, does not capture whether spending results in any actual benefit to the targeted population. Corruption and inefficiency may prevent actual delivery and thus undermine the strength of patron-client networks. Another type of indicator is state-sponsored infrastructure, such as roads and schools (Burgess et al., 2010; Kramon \& Posner, 2010). However, the effective provision of services entails two tasks: providing access to services (that is, through infrastructure) and sustaining the delivery of these services. Defunct services may actually generate grievances rather than instill support. Other studies have investigated redistribution using indicators such as enrollment, literacy, or child mortality rates. The provision of education or health care is, however, often shaped by the interventions of international or private actors (Kramon \& Posner, 2010).

We use geographical variations in electricity flows in times of national power shortages to construct our indicators for selective goods provision. We believe that this conceptualization offers several potential advantages over the indicators presented above. First, using information on flows of power allows us to capture the actual output of service provision. Second, contrary to other goods, electricity is in most cases more directly related to government action given that the ruling elites in many developing countries monopolize - or are at least heavily involved in - the electricity sector. Third, we believe that focusing on variations in the provision of this scarce good allows us to capture selective redistribution more persuasively. As argued above, in times of resource abundance, ruling elites may be inclined to carry out a mass co-optation strategy. However, the scarcer the resources to be distributed, the more important it is to make decisions about who receives what. Thus, the allocation of goods in times of limited availability should provide a clearer picture of the regime's priorities in terms of preferential treatment.

Thus, we investigate geospatial connections between electricity flows in a time of power scarcity (2007-09) and the likelihood of violence during the Syrian civil war.
We do not argue that variation in the access to electricity itself has been responsible for violence - people certainly did not rise against the regime in 2011 because of previous power shortages. We believe, however, that the state's distribution of electricity has not been random but rather a more general strategy of redistribution intended to sustain the patron-client relations that the stability of the regime has been based on. Thus, we use the spatial unevenness in the provision of electricity to identify areas that have been integrated into such patron-client networks.

In the next sections, we demonstrate that such an approach makes good sense for the case of Syria. First, we provide a short overview of the events that led to the civil war and shaped its course. Second, we illustrate the politics of redistribution under the $\mathrm{Ba}$ 'athist regime, demonstrating that the strategic and uneven distribution of material goods has been an essential feature of Syrian politics. Third, we outline some essential characteristics of the Syrian electricity sector, which has traditionally played a major role in this strategy.

\section{Syria in the Arab Spring: From uprising to civil war}

The initial protests in Syria were triggered in the southern city of Dar'a in mid-March 2011, when a group of teenagers were arrested and tortured for writing the motto of the Arab Spring ('the people want the downfall of the regime') on house walls. In reaction, the families and tribal leaders took their protest to the streets. Security forces shot at the demonstrators, killing numerous people and causing further protests that resulted in the destruction of public facilities and private property. The regime attempted to quash the growing protests with massive repression but only succeeded in spreading the protests to the surrounding villages and cities in the southern governorate of Hawran (International Crisis Group, 2011a, 2011b: 12-13; Leenders \& Heydemann, 2012; Balanche, 2013).

After March 2011, the protests gradually spread to almost all governorates in Syria. As the months went by, a clear militarization of the civil and peaceful antiregime protests could be observed (International Crisis Group, 2012a,b). By early 2012, the violent political standoff had escalated into a massive civil war. Regime forces continued their assaults on the rebels' positions. They managed to recapture the coastal city of Latakia early on and reconquer some districts in Homs and Idlib later. The rebels, on the other hand, dominated the Syrian territories along the Turkish border, the rural countryside around the central cities of Hama and Homs, the 
outskirts of Damascus, and the area around the southern city of Dar'a. The armed opposition has been, however, unable to overthrow the regime by military means. The uprising's increasing militarization - accompanied by its 'confessionalization' along Sunni-versus-Alawi lines (Balanche, 2011; International Crisis Group, 2012a,b) - has been countered by the regime's sustained use of harsh repressive measures. From March 2011 to the fall of 2012, Syria's uprising transformed from a semi-urban, peaceful uprising to a professionalized, very violent rebellion that has become a brutal civil-war stalemate.

\section{The politics of redistribution in $\mathrm{Ba}^{\text {'athist Syria }}$}

The Ba'ath party's takeover in Syria in 1963 signified a drastic shift in rural-urban relations and, in particular, the rise of the rural periphery. The transformation of the Syrian countryside, however, has been an uneven process. For instance, the Ba'athist regime invested heavily in jobs, electricity, schooling, and health services in those regions where it had a strong foothold - often via asabiya (primordial group solidarity) ties - and which it considered crucial for political stability. One notable example of a region that profited significantly from developmental measures is the northwestern governorate of Latakia, from which approximately $75 \%$ of the Alawi population hail (Van Dam, 2011: 9). Similarly, the southern region of Hawran (including the provincial town of Dar'a), the countryside around Aleppo, and the northeastern area of Deir az-Zor all profited from the Ba'athist regime's redistribution strategy (Perthes, 1997: 183; for detailed figures see Van Dam, 2011).

Such targeted redistribution - together with repression and ideological legitimation strategies - was the core technique of political control under Hafiz al-Asad. After coming to power in November 1970, he continued to reward those regions that constituted the traditional backbone of the regime (Perthes, 1997: 181-185). Representing the more pragmatic wing of the Ba'ath Party, President al-Asad also developed good ties with the Sunni bourgeoisie in Damascus right from the beginning of his rule by leaving their privileges largely untouched and even granting them new ones via the so-called infitah, the 1970s policy of economic liberalization. While this selective economic opening alienated the more radical, Arab socialist elements of the $\mathrm{Ba}^{\text {'ath }}$ party, the strategy nevertheless paid off from a regimemaintenance perspective, as the conservative Damascene bourgeoisie remained largely silent - and thus loyal - in the context of the Sunni-Islamist antiregime uprising that ended with the Hama massacre in 1982. In contrast, several important religious-conservative merchants of the souk (traditional market) in the northern city of Aleppo supported and, in some cases, even joined the antiregime rebellion. This was arguably due to the fact that they had not been catered to in the same way as their Damascene peers.

In July 2000, Bashar al-Asad succeeded his father, taking over the Syrian presidency as well as the leadership of the armed forces and the Ba'ath party. He not only had to position himself within the inherited authoritarianpersonalist system (Hinnebusch, 2011), but also had to tackle a number of new socio-economic and demographic challenges. Throughout the first decade of the 21 st century, the new regime pursued wide-ranging neoliberal economic reforms, including the privatization of state companies, a hiring freeze in the state administration, and the cutting of subsidies. These measures had harsh negative effects on large parts of the population (Haddad, 2012; Hinnebusch, 2012).

According to Fabrice Balanche (2011), it was precisely the decreased availability of financial resources in times of economic liberalization that contributed to the continuing and in some cases increased importance of patron-client networks. Overall, the initial decade of this century saw the end of the mass provision of goods and the transition to targeted goods provision as a central technique for political control (International Crisis Group, 2011). Examples of how this plays out locally abound: Balanche (2009) holds that key decisions about local state service provision - such as the building of a school or a health center, electricity connections, or the exact routing of a street - depend crucially on clientelist ties and, more broadly, follow a regime-maintenance logic. De Châtel (2014) shows that during the harsh drought years of 2006 to 2009 in the agriculture-based northeast, the regime provided emergency help first and foremost to those selected, well-connected farmers who had already profited from the distribution of state land and subsidized fertilizers (see also Balanche, 2011). In short, all kinds of services have been distributed according to a specific political logic: sustaining the patron-client networks that have become ever more important for the regime's stability (Balanche, 2009: 124). We focus on one of these services - namely, the provision of electricity.

\section{Electricity provision in Syria}

The electricity sector in Syria is firmly in the hands of the state. Although announcements have been made regarding gradual restructuring and privatization, the regime's Ministry of Electricity and its subordinate agencies were 
the only relevant actors in the sector when the uprising began (World Bank, 2009). The energy sector is not only controlled by the state but has also traditionally played a pivotal role in the regime's selective redistribution policy. When the Ba'ath Party seized power in the early 1960s, it launched a massive service-provision campaign in order to drum up broad public support (Goulden, 2011). As a consequence, the rate of electrification increased from 2\% in 1963 to today's impressive 99\% (Goulden, 2011; World Bank, 2009). ${ }^{2}$

According to information from the US Energy Information Administration, however, Syria's net energy consumption dropped suddenly and substantially around 2008 (Energy Information Administration, 2011). Qualitative accounts from this period confirm the electricity crisis and the substantial power cuts (Economic Intelligence Unit, 2008, 2009a,b). ${ }^{3}$ As electricity became a scarce resource, the regime had to take decisions on allocation, identifying those regions that would receive electricity and those that would not. Press reports underscore the fact that the distribution of electricity during this time was not driven by technical factors but by a specific policy of rationing. Rationalization plans were prepared and had to be approved by the central government (Oxford Business Group, 2010; BBC Monitoring Middle East, 2007). Power cuts did not happen ad hoc but were planned by state electricity agencies and announced by local newspapers in advance. Blackouts could last up to five hours a day, with substantial variation across suburbs (Naylor, 2007; Agence France Presse, 2009; Xiaohua, 2007). In 2009 the Ministry of Electricity launched a tender for generators to compensate for the reduced capacities of public networks. These activities, however, focused on selected urban areas only - namely, Damascus, Homs, Hama, Aleppo, and Latakia (Economic Intelligence Unit, 2009a,b). Given that the deliberate and politically motivated allocation of power cuts has also been reported since the beginning of the uprising in $2011,{ }^{4}$ it comes as no surprise that the Ministry of Electricity has been added to the EU sanctions list due to

\footnotetext{
${ }^{2}$ According to data from the 2004 national census, total access to electricity has been around $97 \%$. The deviation from the numbers provided above may represent another slight increase from 2004 to 2009.

3 The background of the crisis is manifold. It is likely that while demand increased constantly, Syria's own generation capacity decreased (World Bank, 2009).

${ }^{4}$ In 2012 The Syria Report described how the Ministry of Electricity increased and decreased power outages in various regions of the country (Syria Report, 9 July 2012, cited after Lyme, 2012).
}

its alleged use of power cuts as a means of repression (European Union, 2012).

Due to the state's control over electricity distribution and the regime's history of using the distribution of all kinds of services - including electricity - strategically, we argue that redistributive decisions made by the ruling regime during the period of severe power shortages (2007-09) should indicate which subdistricts were particularly favored by the ruling elite. In the following section, we explain how we have empirically analyzed whether these subdistricts displayed a lower risk of violence in the early phase of the Syrian civil war.

\section{Design, data, and results}

Our analysis is based on a newly generated dataset of Syrian subdistricts (Arabic: nawahi, sg. nahiya). From the total of 274 subdistricts, we excluded the nine Golan Heights subdistricts due to their specific political status and our assumption that the conflict dynamics here are different from other areas in the country. Moreover, we discarded four subdistricts due to their geographic specificities: the island of Arwad and the three subdistricts of Haritana, Jerablus, and Tall Daww, which each consist of two geographically separated areas. This left us with a total of 261 subdistricts out of 274 , located in 13 of the country's 14 governorates.

\section{The dependent variable: Occurrence of violence}

Our dependent variable is the occurrence of violence during the first 18 months of the Syrian civil war, from March 2011 to November 2012. To measure it, we make use of crowdsourcing data. The basic idea of crowdsourcing is to gather information in a decentralized way, relying on information provided by people 'on the ground'. People submit their observations by email or directly through various online platforms. Such systems have been used in a variety of cases, notably for the observation of violence or electoral processes. ${ }^{5}$

We used the data from an open, online platform called Syria Tracker, which is part of the larger Humanitarian Tracker project - a non-political, non-partisan organization. Reports on fatalities can be filed in Arabic or English and include information on the exact location (either by description of the location or pinpointing on a digital map). The Syria Tracker team claims to make all possible efforts to clean the data of duplications by

\footnotetext{
${ }^{5}$ For example, to monitor elections in Liberia (http:// liberia.ushahidi.com/), or violence in Sudan (https://jan30sudan.crowd map.com/).
} 


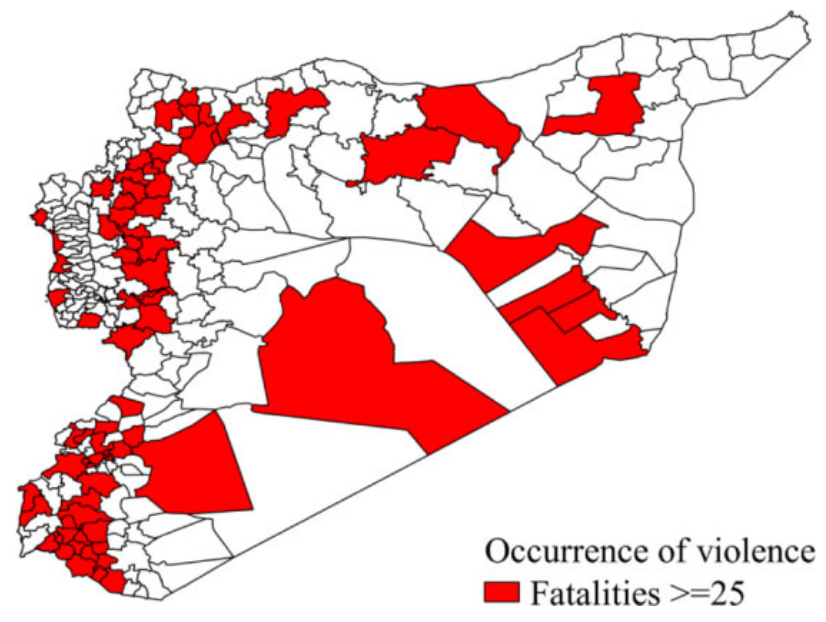

Figure 1. Geographical distribution of fatalities in Syria, March 2011 to November 2012

comparing the information provided in the reports. Moreover, information from various online sources is used to complement the events that have been reported via the Syria Tracker platform. We critically discuss these data and compare them with information from other sources in a separate online appendix.

For our main dependent variable, we collapsed fatality data into a binary indicator for the occurrence of violence for the entire period of analysis, from the beginning of the uprising in March 2011 to November 2012. We set the threshold for positive coding of the variable at 25 reported deaths - in line with analogous country-level thresholds (Gleditsch et al., 2002). We are aware that collapsing fatality counts into a dichotomous variable comes at the cost of losing substantial amounts of information from the data. We believe, however, that there are good theoretical reasons for focusing on a binary variable for the occurrence of violence. Whereas preferential treatment by the ruling elite may play an important role in explaining where violence occurred, we assume that other factors are more relevant in explaining where violence has been particularly intense. Put differently, while we argue that inclusion in and exclusion from patronclient networks can contribute to explaining why violence erupted in some areas but not in others, we find it less plausible that patron-client networks can explain variations in the severity of fighting across subdistricts. While we therefore concentrate our main models on a binary outcome variable, we have tested a number of alternative specifications in the section on robustness checks, including count models using the original fatality counts as outcome variable. As expected, the results of the count models are weaker but mirror the overall findings of the main models presented below. The following illustration depicts the geographical distribution of violent events across Syria's subdistricts.

\section{The independent variable: Access to electricity}

The Defense Meteorological Satellite Program's Operational Linescan System provides data from highresolution satellite images of the earth at night, displaying geographical variations in observable nightlights in cities, towns, and other sites with permanent lighting, including gas flares. Among others things, these pictures are used to produce annual composite images; pictures containing clouds or ephemeral events are discarded. The respective digitized images contain information on the annual average brightness per 30 arc-second grid. The data values per pixel range from 0 to 63 (NOAA, 2013).

The specific advantage of these data is that they have been produced independently of local political interference. Moreover, they provide information beyond the availability of public electricity infrastructure - namely, on the regular flow of electrical power converted into observable outdoor lighting. The images provide comparable data on a yearly basis, allowing for consideration of temporal variations in light output (Min, 2009).

These data have been used before to develop indicators of electrification (Min, 2009) and socio-economic development (Shortland, Christopoulou \& Makatsoris, 2013). While we believe that nightlights are persuasive indicators for these concepts, we are interested in another aspect. We do not concentrate on static measures or on longer-term developments but on the geographical distribution of nightlight outputs in moments of power shocks. Focusing on very short-term variations - the energy crisis of 2007-09 - allows us to minimize the risk that observable spatiotemporal variations stem from population movements, socio-economic development, or ongoing electrification.

In Syria, the residential sector is the biggest consumer of electricity (World Bank, 2009), with approximately $70 \%$ going to lighting, refrigerators, and televisions (Karaki et al., 2005). Overall, electricity is the main power source for lighting in Syria. Consequently, observable nightlights should be a good indicator of people's actual access to electricity across time and across geographical areas.

As a first step, we used Geographic Information Systems software to generate the annual nightlight emissions for the whole of Syria for the years 2004 to 2009 - the five most recent years for which nightlight images from 


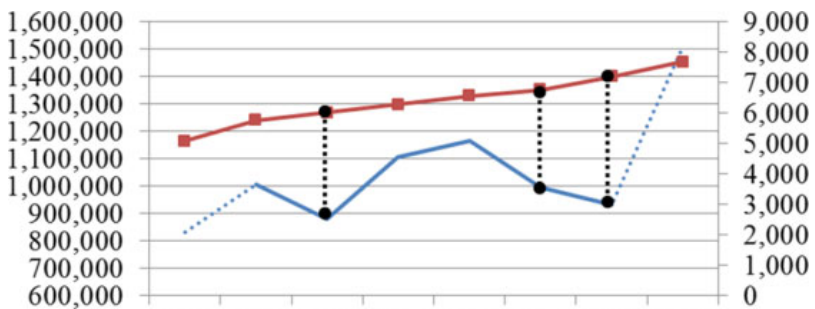

20032004200520062007200820092010

Figure 2. Total nightlight emission and electricity demand in Syria, 2003 to 2010

a single satellite (F16) have been available. Comparing nightlight data across satellites may be problematic due to differences in light detection capabilities. For illustrative reasons, however, we have also included data for 2003 and 2010 in Figure 2 to give some indication of previous and subsequent trends. Temporal nightlight variations are represented by the lower (blue) line in Figure 2 (primary axis, total lights values of all pixels within the Syrian borders).

As the need for planned power cuts ('load shedding') does not just depend on the availability of electricity, we also investigate the temporal variation in demand for electricity - plotted as the upper (red) line in the same graph (secondary axis, kilowatt hours; data from World Bank, 2009). The graph shows that there was a drop in nightlight emissions from 2004 to 2005. This one-year decrease was, however, less pronounced than that in the period from 2007 to 2009 under investigation. Moreover, demand was substantially higher at the time of the second drop. This may also explain why qualitative reports have put so much emphasis on power cuts during the 2007-09 energy crisis. The graph lends support to the argument that we are actually looking at a relevant time period: in the years 2007-09 Syria experienced the most recent and most substantial decline in the availability of electricity prior to the uprising in 2011. Thus, patterns of electricity redistribution during this period should provide a valid proxy for patron-client networks before the beginning of the violent conflict in 2011 .

As a second step, we calculated mean light outputs for each Syrian subdistrict separately. ${ }^{6}$ When we inspect the light values more closely, we notice that

\footnotetext{
${ }^{6}$ The light mean refers to the sum of the light values of all pixels within a subdistrict divided by the total number of pixels. Thus, by using mean values, we account for the differing size of subdistricts.
}

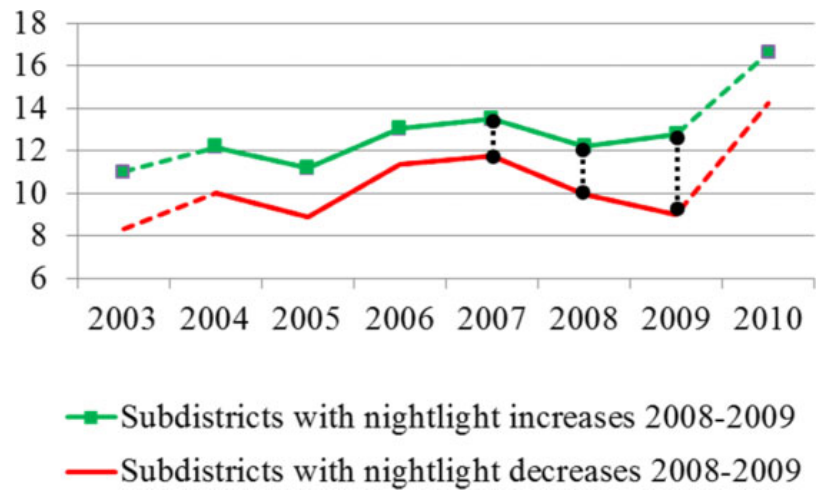

Figure 3. Subdistrict nightlight emission in Syria, 2003 to 2010

light outputs diminished in nearly all subdistricts from 2007 to 2008. However, some subdistricts started to recover in the period 2008-09, whereas most others suffered further output losses. Figure 2 illustrates the development of the annual mean light outputs for those subdistricts that experienced an increase of energy availability from 2008 to 2009 and those that experienced further losses. We see that overall the subdistricts represented by the upper line also had a higher mean light output and experienced less pronounced losses from 2007 to 2008 . Given the measures taken by the Syrian regime in 2008 and 2009 to counter the consequences of the crisis, we interpret these observations as fairly consistent indications that a specific group of subdistricts was privileged in terms of general access to electricity. Accordingly, we use these observable variations in light outputs as an indicator of the preferential treatment of some Syrian subdistricts by the ruling elite. In the online appendix, we provide a more technical discussion of why we believe that these variations are not due to technical factors.

We have constructed three separate independent variables with the aim of capturing various facets of changes and differences in light outputs, thereby increasing the robustness of our operationalization. The first indicator is the absolute change in mean light outputs from 2007 to 2009. As the absolute losses or gains may be influenced by the original light output in 2007, our second indicator is the change rate, dividing the absolute increase or decrease by the mean light output in 2007 . The final indicator is a dummy variable that differentiates between those subdistricts that experienced an increase in mean light outputs from 2008 to 2009 and those that did not. Figure 4 plots this last variable to illustrate the spatial variations in increases and decreases in light outputs during the electricity crisis. 


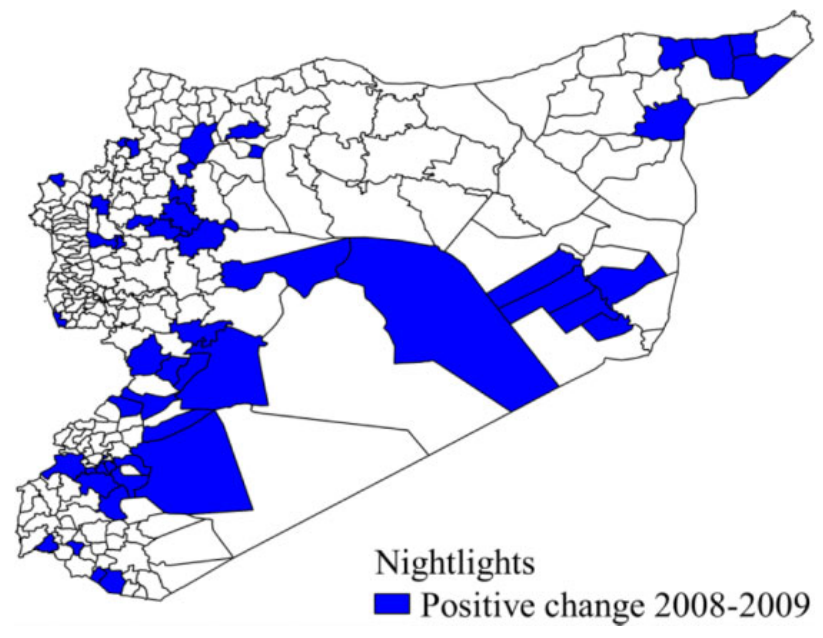

Figure 4. Nightlight increases in Syrian subdistricts, 2008 to 2009

\section{Alternative explanations and control variables}

The indicators we have used for our control variables mainly stem from the country's last population census, undertaken in 2004. Although socio-economic and political features of the subdistricts may have changed in the seven-year period between the census and the beginning of the uprising in 2011, we assume that this time span was too short for any fundamental changes in the differences across subdistricts to have occurred. As our analyses only exploit such geographical variations, we are confident that the census data provide effective proxies for certain essential variables. If not explicitly stated otherwise, the information for our control variables comes from the census.

Countries and subnational administrative units display a higher risk of experiencing political violence when more people live within their boundaries (Collier \& Hoeffler, 2004). We have included log-transformed population size in our analyses in order to account for excessive variations in population size across Syrian subdistricts.

The Syrian civil war evolved out of mass protests that began in the country's semi-urban areas and eventually spread to the urban centers. We have therefore included information on subdistricts' degrees of urbanization in our analyses. Following the thresholds used by the United Nations, our urbanization variable represents the share of the population living in cities with more than 20,000 inhabitants.

The theoretical and empirical literature on political violence has emphasized the role of grievances stemming from low socio-economic development (see Gurr, 1993). We consider primary school enrollment rates per subdistrict as a proxy for development levels.
Our main independent variables can only mirror variations in the public provision of electricity if people primarily use power from public networks, rather than from private generators. We have thus included the share of people with access to the state's electricity network as a control variable.

Studies that focus on opportunities for rebellion emphasize the role of factors that facilitate recruitment into armed groups (Collier \& Hoeffler, 2004). We include information on male unemployment rates per subdistrict in our analyses.

Previous quantitative analyses of the subnational level demonstrate that violence is less likely in areas where the state maintains an effective presence (Buhaug, 2010). The Syrian census includes information on the share of people working for the state. We leverage this information to control for variations in state presence across subdistricts.

We use information on the Syrian road network provided by the UNDP to proxy accessibility. Using GIS software, we have calculated the number of road kilometers per subdistrict and divided it by the size of the respective subdistrict areas.

It has been argued that Sunnis have formed the backbone of resistance against the regime. To the best of our knowledge, no reliable data beyond rough approximations exist on the exact size and settlement areas of the various communities. Moreover, most regions of Syria have actually been ethnically and/or religiously mixed. As part of a larger mapping project (Gulf 2000), Michael Izady has generated a map displaying broad settlement areas of all religious communities (Izady, 2012). We exploit the map to construct a dummy variable that takes on the value 1 for subdistricts that enclose Sunni settlement areas and to construct another similar variable for Alawi settlement areas. ${ }^{7}$

Finally, in the case of Syria, studies have emphasized that local smuggling networks in the southern and northern border districts have been a major resource for the mobilization of resistance (Leenders \& Heydemann, 2012). Thus, we control for the distance of each subdistrict's center point to the nearest international border.

Although the census provides a series of relevant socio-economic data, we did not have access to reliable

\footnotetext{
${ }^{7}$ As an alternative measure we constructed similar variables based on data provided by the Geo Ethnic Power Relations Dataset (Wucherpfennig et al., 2011). The results of the respective estimations are reported in the online appendix (see Table AXV). Our main explanatory variables are not affected by this alternative measurement.
} 
Table I. Occurrence of violence in Syrian subdistricts, March 2011 to November 2012

\begin{tabular}{|c|c|c|c|c|}
\hline & (1) & (2) & (3) & (4) \\
\hline Gov. employees & $-0.008(0.662)$ & $-0.010(0.627)$ & $-0.005(0.805)$ & $-0.021(0.316)$ \\
\hline Sunni & $0.355(0.597)$ & $0.282(0.691)$ & $0.323(0.640)$ & $0.152(0.832)$ \\
\hline Alawi & $0.026(0.977)$ & $-0.040(0.969)$ & $0.118(0.903)$ & $-0.116(0.905)$ \\
\hline Prim. enrollment & $0.026(0.868)$ & $-0.049(0.761)$ & $0.006(0.971)$ & $0.066(0.700)$ \\
\hline Border dist. (log) & $-0.212(0.457)$ & $0.000(0.999)$ & $0.021(0.946)$ & $0.005(0.987)$ \\
\hline Urbanization & $2.300 *(0.011)$ & $2.681^{* *}(0.005)$ & $2.553^{* *}(0.007)$ & $2.587^{* *}(0.006)$ \\
\hline Electricity & $0.011(0.925)$ & $-0.010(0.929)$ & $0.075(0.555)$ & $0.021(0.861)$ \\
\hline Unemployment & $0.003(0.956)$ & $-0.007(0.900)$ & $-0.010(0.850)$ & $0.008(0.881)$ \\
\hline Road density & $-2.018^{\dagger}(0.059)$ & $-2.428^{*}(0.046)$ & $-1.535(0.162)$ & $-2.026^{\dagger}(0.073)$ \\
\hline Population (log) & $1.854^{* * *}(0.000)$ & $1.758^{* * *}(0.000)$ & $1.924^{* * *}(0.000)$ & $1.742^{* * *}(0.000)$ \\
\hline Lights change & & $-0.434^{* *}(0.003)$ & & \\
\hline Lights rel. change & & & $-5.740 *(0.029)$ & \\
\hline Lights pos. change & & & & $-1.849^{* *}(0.008)$ \\
\hline Observations & 247 & 247 & 247 & 247 \\
\hline AIC & 135.726 & 127.967 & 132.859 & 129.376 \\
\hline 11 & -57.863 & -52.983 & -55.430 & -53.688 \\
\hline
\end{tabular}

$p$-values in parentheses; ${ }^{\dagger} p<0.1,{ }^{*} p<0.05,{ }^{* *} p<0.01,{ }^{* * *} p<0.001$.

data for other potentially relevant factors - for example, the political affiliations of the executives of the regional power suppliers across the country's 14 governorates. To account for these and other social, economic, or political variations, we have included governorate-level fixed effects in our model. More information on our empirical strategy is provided in the next section. ${ }^{8}$

\section{Model specification and results}

In analyzing a binary variable, we have used logit models, including governorate-level fixed effects. As part of our robustness checks, described below, we have performed alternative estimations using different models. Table I presents estimation results for all three variations of our independent variable in our primary fixed effects model.

Column 1 presents the results of our baseline model without the inclusion of any nightlight variable. We find that population size and urbanization play a highly significant role. Both are positively related to the risk of violence and, thus, mirror the theoretically expected connection. Neither the presence of Sunni settlement areas nor the share of people that have access to the national electricity grid seems to matter. The former may be because the confessional dimension of the conflict did not play a prominent role in the early phase of the uprising in Syria but gradually gained in importance as

\footnotetext{
${ }^{8}$ We have also calculated a variable that totals the number of fatalities in all neighboring subdistricts and included it as an additional control (see Table AXVI).
}

fighting became more intense. The fact that access to public electricity networks does not seem to be relevant underlines the claims made above: whether the share of a subdistrict's population with access to the electricity grid is a little lower or higher than the average may say nothing about the regime's policy towards the subdistrict.

Column 2 estimates the logit model with our measure of changes in light outputs between 2007 and 2009, controlling for confounding factors and including fixed effects at the governorate level. The coefficient is statistically significant below the $1 \%$ level and negative, indicating that the less a subdistrict experienced power losses during the period under investigation, the lower the probability that it experienced violence. Column 3 presents the results for the changes in light output in relation to the original output in 2007. Again, we find a statistically significant association between changes in light output and the likelihood of violence. From all three conceptualizations of our variable, changes relative to the original light output are weakest, with statistical significance below the $5 \%$ level. In column 4 , the nightlight dummy variable differentiates between those subdistricts where light output further decreased after the initial shortage in 2007 and those subdistricts where light output started to increase again. We find the expected connection with the likelihood of political violence, statistically significant below the $1 \%$ level.

Because we deal with rather technical and abstract indicators for our explanatory variables, we do not aim to provide exact coefficients for the strength of the correlations found. To demonstrate, however, that the effects 
are different from zero, we simulate marginal effects for our main models. Predicted probabilities cannot be directly calculated from the conditional fixed effects logit models presented in the results table. Instead, we have reestimated the main models with governorate dummy variables (and robust clustered standard errors). The results mirror those presented above (detailed table in the online appendix). In a second step, holding all other variables at their respective means, we have estimated the predicted probabilities per governorate. To provide for a general idea of the strength of the effects, we have calculated their means across all governorates: As we move from the fifth to the 95 th percentiles of our first main variable, the risk of violence drops from $43 \%$ to approximately $4 \%$ on average across governorates. The effects of the two other variables are weaker. The risk of violence drops from $33 \%$ to $4 \%$ in a similar simulation for the nightlight change rate; subdistricts that display an increase in light outputs from 2008 to 2009 show a $16 \%$ lower risk of experiencing violence than other subdistricts. ${ }^{9}$

Before discussing these findings in light of recent qualitative analyses, we implement a series of additional robustness checks to further establish the strength of the findings in the following paragraphs. The detailed results and regression tables are provided in the online appendix.

\section{Robustness checks ${ }^{10}$}

For the operationalization of our dependent variable, we defined a threshold of 25 fatalities. Although this specific number has been widely applied in the coding of violent conflicts at the country level, it is - like all other thresholds - arbitrary. Therefore, we have repeated our estimations with four alternative thresholds $(5,10,20$, and 50 fatalities). The results correspond to those obtained with our initial operationalization but are weakest with the threshold set at five fatalities (see Tables AII-AV).

For our dependent variable, we have considered fatalities during the period from March 2011 to November 2012. The end point of the period has been defined by the time we began our analyses and the last month for which data were available. Thus, to control for this rather

\footnotetext{
${ }^{9}$ For the latter two variables, effects are significant only in single governorates. We believe, however, that this has mainly been due to the fact that we had to predict probabilities on the governorate level and that many of them provide a low number of observations and little variation in the outcome variable.

${ }^{10}$ Wherever possible, we have clustered standard errors at the governorate level.
}

arbitrary time frame, we have performed analyses using another end point, re-estimating our main model for a shorter period - from March 2011 to February 2012. Again, our initial findings are confirmed (see Table AVI in the online appendix).

To further demonstrate that our findings are not related to the operationalization and measurement of our outcome, we have estimated actual count models using two different sources: the original fatality counts provided by Syria Tracker and event data from the Global Data on Events, Location and Tone (GDELT) dataset, which is based on reports from international news sources (Leetaru \& Schrodt, 2013). More information on the latter data as well as the creation of the Syria data subset that we used is provided in the online appendix. Our variables perform more weakly but in a similar way in the count models (see Tables AVII-AXI in the online appendix). Most notably, while the variables generally show the right sign in the models using GDELT data, we find a significant association with total counts only for absolute nightlight changes. ${ }^{11}$

Because we have emphasized the urban character of the early stage of the Syrian civil war, it may be the case that the country's largest cities display specific links between access to electricity and reports on fatalities. Accordingly, we have excluded the governorate capitals from our sample and repeated our analyses without any major changes to our results (see Table AX).

Finally, we have tried to rule out some plausible alternative explanations for the correlation between nightlight change and occurrence of violence. As mentioned above, the nightlight data include gas flares. Syria is an oil-producing country with numerous oil and gas fields in the eastern part of the country. Lights emanating from gas flares will not be affected by power cuts. Such strategic resources may also be particularly well protected by security personnel, leading to lower risks of violence occurrence. We did not possess detailed data on the exact location of oil and gas fields; the petroleum dataset provided by Lujala, Rod \& Thieme (2007) only contains information on their approximate location. We compared the data with maps retrieved from the Syrian oil company Al Furat Petroleum. Based on these two sources, we identified five governorates with varying

\footnotetext{
${ }^{11}$ Allison \& Waterman (2002) show that fixed effects count models, as implemented by STATA, do not in fact control for time-invariant unobserved factors. We have estimated STATA built-in fixed effects and dummies. In the latter GDELT models, our main explanatory variables show the right sign but are not statistically significant.
} 
numbers of oil and gas fields. As a robustness check, we excluded these governorates from the dataset and repeated our standard estimation. For the remaining 164 observations, the role of our light output variables was unchanged (see Table AXI).

A similar argument as for oil can be made for the role of industry. Industrial production consumes approximately 37 percent of Syria's total energy. The state may have tried to avert power cuts in highly industrialized regions for economic reasons. Again, these areas may also have large numbers of security forces due to their economic importance. This may drive associations between nightlight change and the risk of violence. We used census information on the share of people working in the industrial sector as a proxy for subdistrict industrialization, without any effect on our main variables (see Table AXII).

In the online appendix we discuss why we believe that variations in nightlight emissions are not determined by technical factors alone. Nonetheless, for a more systematic robustness check, we have estimated an additional model that controls for the distance of each subdistrict's center from the nearest power station. These stations may be situated in regime strongholds rather than the periphery. The greater the distance to these stations, the lower the quality of electricity provision (network losses may increase with distance) and the lower the repressive capacity of the state. This additional control has no effect on our explanatory variables (see Table AXIII).

Finally, the share of households with private generators is likely to be higher in wealthier regions. These regions may suffer less from electricity shortages and have higher opportunity costs for rebellion. If this is the case, we may not be capturing the regime's co-optation strategy but rather spatial economic disparities. We have thus controlled for the subdistrict-level share of people who own the house they live in, without significant changes to our main results (see Table AXIV).

\section{Discussion of results}

Our empirical findings lend support to our hypothesis that patterns of selective goods provision correlate with geographical patterns of violence in Syria. We believe that our indicators provide a persuasive proxy for the selective goods provision associated with patron-client networks. However, we cannot make strong causal claims based on a cross-sectional analysis alone. We therefore briefly discuss our findings in light of previous qualitative analysis of the actual role of patron-client networks in the subnational distribution of violence during the civil war. The aim of this section is to illustrate that our arguments and findings resonate well with previous qualitative evidence.

Detailed qualitative studies of different Syrian localities since early 2011 strongly indicate that villages, towns, or cities without ties to dense regime-based patron-client networks before the uprising have indeed been very likely to experience violence in the early phase of the civil war. The southern provincial city of Dar'a, in which the uprising began in mid-March 2011, is a case in point. In what was traditionally a Ba'athist stronghold and the administrative center of the Hawran governorate, local state institutions gradually withdrew from the city and the adjacent region since the 1990s, thereby weakening the previously strong patron-client ties between the regime and important local constituencies (Leenders \& Heydemann, 2012). The local political economy in and around Dar'a declined, and the regime's local 'presence took the shape of corrupt and incompetent civilian officials, equally rapacious members of the security forces and a rather provocative camp staffed with Allawite [Alawi] officers and their families' (International Crisis Group, 2012a). This was a far cry from the Ba'athist regime's previous multifaceted existence in Dar'a. Early on in the uprising, the protesters addressed this constellation directly. They called for the withdrawal of the corrupt governor and the local head of security and demanded state measures to better the socio-economic malaise (International Crisis Group, 2012a; Leenders \& Heydemann, 2012).

Beyond Dar'a, and as explained above, the uprising quickly spread to other villages, towns, and provincial cities across Syria. While a host of context-specific features contributed to the respective dynamics of local conflicts, a determining factor in provincial cities such as Idlib, Jisr Ash-Shughour, Maarat an-Nu'man, Rastan, and Talbissah was - in Fabrice Balanche's words - 'the disinvestment of the state' (2013: 8). As these examples from central and northern Syria show, the uprising and ensuing civil war developed against the background of the gradual withdrawal of the local state from several rural and semi-urban regions, which ended a - albeit partial - favorable regime redistribution policy. In a way, the Syrian protesters initially reacted to this process by demanding that the respective localities be reincorporated into regime-based clientelist networks. As Balanche (2013) argues, the geographical variation in this 'disinvestment' played an essential role in determining whether or not villages engaged significantly against the state during the uprising.

The nexus between material redistribution and the likelihood of violence in the civil war can be observed not only across villages, towns, and cities, but also across 
different neighborhoods and quarters within the same city. As Salwa Ismail recently noted regarding the Syrian capital, 'Relations with the regime and the demographic composition of quarters are the main variables at play in the differentiated responses to the Uprising observed in Damascus and elsewhere' (Ismail, 2013: 883). Informal quarters on the outskirts of the city - such as Mezza 86, in which the $\mathrm{Ba}$ 'athist regime has continuously invested since the settlement's establishment in the 1970s - have therefore remained calm during the emerging civil war. In contrast to Mezza 86, similarly structured informal neighborhoods such as Barzeh or Qaboun, which were not part of the regime's patron-client networks, have become strongholds of the violent rebellion (Ismail, 2013). A similar effect of the regime's differential treatment on the likelihood of violence in the ensuing civil war can also be observed in Damascus's traditional quarters Midan and Rukn al-Din (Ismail, 2013), as well as in the capital's outskirts, especially in the east and south (International Crisis Group, 2011a).

Taken together, there is ample qualitative evidence supporting the claim that the selective redistribution of scarce resources took place in areas where the regime had strong clientelist networks. Those areas with weak ties to these networks faced an increased risk of violence during the civil war; those areas with strong ties have remained calm.

\section{Conclusions}

Our analysis confirms earlier findings from cross-country analyses of how the redistribution of state resources impacts the risk of violence - that is, how patron-client networks in which political support is provided in return for preferential treatment influence the risk of violence against the state. Although some subdistricts contradict our theoretical argument, our empirical analyses provide consistent and robust evidence that inclusion in patron-client networks and selective redistribution have played a role in reducing the likelihood of certain subdistricts experiencing violence during the early phase of the civil war in Syria. We are thus able to provide support for the hypothesis that selective redistribution can contribute to reducing the risk of violent opposition in beneficiary regions.

Empirically, we provide support for the growing number of analyses that make use of new, rather unconventional data sources, such as nightlights and crowdsourcing. Although we are aware of the potential shortcomings and risks of using such data, we have shown how they can contribute to analyses in settings marked by the limited availability of reliable data - for example, in authoritarian regime contexts or situations of open warfare. In terms of the more specific operationalization of material redistribution, our analyses demonstrate the need to consider the actual provision of respective services and not general access alone. In our case, it was not access to the national electricity grid but rather the variation in the provision of electricity that mattered. Finally, we provide an example of how temporal developments (for example, previous changes in nightlights) may be exploited in order to measure dynamics of redistribution that cannot be captured using static data alone.

Building on these insights, future research on the nexus of patron-client relations, selective redistribution, and political violence could proceed along three avenues. First, future research should study more than one public good. The selective distribution of other goods or of 'packages' of goods should enable the more robust operationalization of strategic decisions on material redistribution by ruling regimes. Second, our analysis focuses on one country alone. Cross-country, subnational analyses could scrutinize our findings. The global availability of nightlight data as well as the growing number of geographically disaggregated event datasets may allow for such analyses in a selected number of cases. Third, we have examined our hypothesis in the context of a highly authoritarian regime in a society divided along multiple lines. Future studies may wish to focus on democratic countries and/or countries with other ethnopolitical features.

\section{Replication data}

The dataset and do-files for the empirical analysis in this article, along with the online appendix, can be found at http://www.prio.no/jpr/datasets. All estimations have been made using Stata version 12.0. Geo-processing has been made with QGIS 2.0.0.

\section{Acknowledgements}

An earlier version of this paper was presented at the Annual Convention of the International Studies Association in San Francisco in April 2013. The authors would like to thank Fritz Rickert for great research assistance, Viola Lucas, Stephan Rosiny, and three anonymous reviewers for insightful comments and productive criticism.

\section{References}

Acemoglu, Daron; Thierry Verdier \& James A Robinson (2004) Kleptocracy and divide-and-rule: A model of personal rule. Journal of the European Economic Association 2(2-3): 162-192.

Agence France Presse (2009) Syria sweats over electricity shortage, 24 August. 
Allison, Paul D \& Richard P Waterman (2002) Fixed effects negative binomial regression models. Sociological Methodology 32(1): 247-265.

Balanche, Fabrice (2009) Clientélisme, communautarisme et fragmentation territoriale en Syrie [Clientelism, communitarism and territorial fragmentation in Syria]. A Contrario 11(1): 122-150.

Balanche, Fabrice (2011) Géographie de la révolte syrienne [Geography of the Syrian revolt]. Outre-Terre 29(3): 437-458.

Balanche, Fabrice (2013) Syrie : Guerre civile et internationalisation du conflit [Syria: Civil war and internationalization of the conflict]. Eurorient 49(May) (http://halshs.archivesouvertes.fr/halshs-00841955).

BBC Monitoring Middle East (2007) Syrian press highlights, 29 January.

Bueno de Mesquita, Bruce; Alastair Smith, Randolph M Siverson \& James D Morrow (2003) The Logic of Political Survival. Cambridge, MA: MIT Press.

Buhaug, Halvard (2010) Dude, where's my conflict? LSG, relative strength, and the location of civil war. Conflict Management and Peace Science 27(2): 107-128.

Burgess, Robin; Rémi Jedwab, Edward Miguel \& Ameet Morjaria (2010) Our turn to eat: The political economy of roads in Kenya. Unpublished paper (http://mitsloan. mit.edu/neudc/papers/paper_294.pdf).

Bussmann, Margit (2009) Staatskapazität und Bürgerkriege: Peitsche oder Zuckerbrot? [State capacity and civil war: Carrot or stick?] In: Margit Bussmann, Andreas Hasenclever \& Gerald Schneider (eds) Identität, Institutionen und Ökonomie: Ursachen innenpolitischer Gewalt [Identities, Institutions and Economy: Causes of Intrastate Violence]. Wiesbaden: VS Verlag für Sozialwissenschaften, 258-282.

Collier, Paul \& Anke Hoeffler (2004) Greed and grievance in civil war. Oxford Economic Papers 56(4): 563-595.

De Châtel, Francesca (2014) The role of drought and climate change in the Syrian uprising: Untangling the triggers of the revolution. Middle Eastern Studies 50(4): 521-535.

Economic Intelligence Unit (2008) Country Report Syria August. London.

Economic Intelligence Unit (2009a) Country Report Syria June. London.

Economic Intelligence Unit (2009b) Country Report Syria July. London.

Energy Information Administration (2011) Country Analysis Brief - Syria.

European Union (2012) Council Implementing Regulation (EU) No 266/2012. Official Journal of the European Union (http://eur-lex.europa.eu/legal-content/EN/TXT/?uri=CEL EX:32012R0266).

Fjelde, Hanne (2009) Buying peace? Oil wealth, corruption and civil war, 1985-99. Journal of Peace Research 46(2): 199-218.

Fjelde, Hanne (2010) Generals, dictators, and kings: Authoritarian regimes and civil conflict, 1973-2004. Conflict Management and Peace Science 27(3): 195-218.
Fjelde, Hanne \& Indra de Soysa (2009) Coercion, co-optation, or cooperation? State capacity and the risk of civil war, 1961-2004. Conflict Management and Peace Science 26(1): 5-25.

Gandhi, Jennifer \& Adam Przeworski (2007) Authoritarian institutions and the survival of autocrats. Comparative Political Studies 40(11): 1279-1301.

Gerschewski, Johannes (2013) The three pillars of stability: Legitimation, repression, and co-optation in autocratic regimes. Democratization 20(1): 13-38.

Gleditsch, Nils Petter; Peter Wallensteen, Mikael Eriksson, Margareta Sollenberg \& Håvard Strand (2002) Armed conflict 1946-2001: A new dataset. Journal of Peace Research 39(5): 615-637.

Goulden, Robert (2011) Housing, inequality, and economic change in Syria. British Journal of Middle Eastern Studies 38(2): 187-202.

Gurr, Ted Robert (1993) Why minorities rebel: A global analysis of communal mobilization and conflict since 1945. International Political Science Review 14(2): 161-201.

Haddad, Bassam (2012) Syria's state bourgeoisie: An organic backbone of the regime. Middle East Critique 21(3): 231-257.

Hinnebusch, Raymond (2011) The Ba'ath party in postBa'athist Syria: President, party and the struggle for 'reform'. Middle East Critique 20(2): 109-125.

Hinnebusch, Raymond (2012) Syria: From authoritarian upgrading to revolution. International Affairs 88(1): 95-113.

International Crisis Group (2011a) Popular protest in North Africa and the Middle East (VI): The Syrian people's slow motion revolution. Middle East/North Africa Report 108. Brussels (http://www.crisisgroup.org/ /media/files/middle \%20east $\% 20$ north\%20africa/iraq\%20syria\%20lebanon/syria/ 108-\%20popular\%20protest $\% 20$ in $\% 20$ north\%20africa $\% 20$ and $\% 20$ the $\% 20$ middle $\% 20$ east $\% 20$ vi $\% 20-\% 20$ the $\% 20$ syrian\%20peoples\%20slow-motion\%20revolution.pdf).

International Crisis Group (2011b) Popular protest in North Africa and the Middle East (VI): The Syrian regime's slow motion suicide. Middle East/North Africa Report 109. Brussels (http://www.crisisgroup.org/ /media/Files/Middle\%20East \%20North\%20Africa/Iraq\%20Syria\%20Lebanon/Syria/109 \%20Popular\%20Protest $\% 20$ in\%20North\%20Africa $\% 20$ and $\% 20$ the $\% 20$ Middle $\% 20$ East $\% 20$ VII\%20-\%20The $\%$ 20Syrian\%20Regimes\%20Slow-motion\%20Suicide.pdf).

International Crisis Group (2012a) Syria's phase of radicalisation. Middle East Briefing 33. Brussels (http://www.crisis group.org/ /media/Files/Middle\%20East $\% 20$ North\%20 Africa/Iraq\%20Syria\%20Lebanon/Syria/b033-syrias-phaseof-radicalisation.pdf).

International Crisis Group (2012b) Syria's mutating conflict. Middle East/North Africa Report 128. Brussels (http://www. crisisgroup.org/ /media/files/middle\%20east $\% 20$ north $\%$ 20africa/iraq\%20syria\%20lebanon/syria/128-syrias-mutatingconflict.pdf).

Ismail, Salwa (2013) Urban subalterns in the Arab revolutions: Cairo and Damascus in comparative perspective. Comparative Studies in Society and History 55(4): 865-894. 
Izady, Michael (2012) Syria ethnic composition (detailed). Map produced for School of International and Public Affairs (SIPA) Gulf/2000 Project, Columbia University (http://gulf2000.columbia.edu/maps.shtml).

Karaki, Sami; Farid Chaaban, Riad Chedid, Toufic Mezher, Ali Hamzeh, Ahmad Harb \& Fayez Abdulla (2005) Electric energy access in Jordan, Lebanon and Syria. World Resource Review 17(3): 410-482.

Kramon, Eric \& Daniel N Posner (2010) Who is favored? How the outcomes one studies affect the answers one gets. Research note prepared for the meeting of the Working Group in African Political Economy, 30 April-1 May (http://www.sscnet. ucla.edu/polisci/wgape/papers/18_Kramon_Posner.pdf).

Kramon, Eric \& Daniel N Posner (2012) Ethnic favoritism in primary education in Kenya. Unpublished paper (http:// cega.berkeley.edu/assets/miscellaneous_files/Posner_WGA PE0313.pdf).

Leenders, Reinoud \& Steven Heydemann (2012) Popular mobilization in Syria: Opportunity and threat, and the social networks of the early risers. Mediterranean Politics 17(2): 139-159.

Leetaru, Kalev \& Philip Schrodt (2013) GDELT: Global data on events, language, and tone, 1979-2012. Paper presented at the Annual Conference of the International Studies Association, April, San Diego, CA (http://data. gdeltproject.org/documentation/ISA.2013.GDELT.pdf).

Levi, Margaret (2006) Why we need a new theory of government. Perspectives on Politics 4(1): 5-19.

Lujala, Päivi; Jan Ketil Rød \& Nadja Thieme (2007) Fighting over oil: Introducing a new dataset. Conflict Management and Peace Science 24(3): 239-256.

Lyme, Rune Friberg (2012) Sanctioning Assad's Syria: Mapping the economic, socioeconomic and political repercussions of the international sanctions imposed on Syria since March 2011. DIIS Report 13. Copenhagen: Danish Institute for International Studies.

Min, Brian (2009) Distributing power: Public service provision to the poor in India. Paper presented at the Annual Conference of the American Political Science Association in Toronto (http://www.yale.edu/leitner/resources/PMF-papers/Min_ India_20091005.pdf).

Naylor, Hugh (2007) Tired of energy ills, Syrians doubt the West is to blame. New York Times 15 August.

NOAA (2013) Earth Observation Group - Defense Meteorological Satellite Program, Boulder (http://ngdc.noaa.gov/ eog/dmsp/downloadV4composites.html).
Oxford Business Group (2010) The Report: Syria 2010. Oxford: Oxford Business Group.

Perthes, Volker (1997) The Political Economy of Syria under Asad. London: Tauris.

Shortland, Anja: Katerina Christopoulou \& Charalampos Makatsoris (2013) War and famine, peace and light? The economic dynamics of conflict in Somalia 1993-2009. Journal of Peace Research 50(5): 545-561.

Taydas, Zeynep \& Dursun Peksen (2012) Can states buy peace? Social welfare spending and civil conflicts. Journal of Peace Research 49(2): 273-287.

Van Dam, Nikolaos (2011) The Struggle for Power in Syria: Politics and Society under Asad and the Ba'th Party, 4th edn. London: Tauris.

Weinstein, Laura (2011) The politics of government expenditures in Tanzania, 1999-2007. African Studies Review 54(1): 33-57.

Wickham-Crowley, Timothy P (1987) The rise (and sometimes fall) of guerrilla governments in Latin America. Sociological Forum 2(3): 473-499.

Wintrobe, Ronald (2000) The Political Economy of Dictatorship. Cambridge: Cambridge University Press.

World Bank (2009) Syrian Arab Republic Electricity Sector Strategy Note. Washington, DC: World Bank.

Wucherpfennig, Julian; Nils B Weidmann, Luc Girardin, Lars-Erik Cederman \& Andreas Wimmer (2011) Politically relevant ethnic groups across space and time: Introducing the GeoEPR dataset. Conflict Management and Peace Science 28(5): 423-437.

Xiaohua, Jia (2007) Syria plagued by electricity deficiency. Xinhua General News Service 8 July.

ALEXANDER DE JUAN, b. 1979, PhD in Political Science (Eberhard Karls University Tübingen, 2010); Research Fellow, German Institute of Global and Area Studies (2012- ); current main interest: violent conflict and state building; most recent articles published in Political Geography, Conflict Management and Peace Science, and Civil Wars.

ANDRÉ BANK, b. 1977, PhD in Political Science (Philipps University Marburg, 2010); Research Fellow, German Institute of Global and Area Studies (2010- ); current main interest: authoritarianism and Middle East conflicts; most recent articles published in Democratization, PVS, and Third World Quarterly. 